\title{
«CARITAS IN VERITATE»: PUNTOS PARA EL DIÁLOGO ENTRE LA TEORÍA ECONÓMICA Y EL MAGISTERIO SOCIAL
}

\author{
ANTONIO PANCORBO DE RATO*
}

\begin{abstract}
Resumen: Dentro del gran evento doctrinal que representa la encíclica de Benedicto XVI, Caritas in Veritate, haciendo hincapié sobre el papel central que el amor y la verdad, el don y la gratuidad deben jugar en una reflexión completa sobre la acción humana, el presente artículo toma la tarea un tanto impopular de identificar aquellas soluciones técnicas que, tal y como se presentan en la Encíclica, pudieran ser discutibles desde el punto de vista de la teoría economía. El artículo no pretende corregir dichas soluciones técnicas, sino simplemente mencionarlas como puntos abiertos al debate entre economistas y moralistas para que entre ambos campos del saber se discutan y finalmente se propongan soluciones que no solo sean moralmente válidas, sino también técnicamente posibles.
\end{abstract}

Palabras clave: Doctrina social, pensamiento económico, estructura de mercado, formación de precios, bienestar, pobreza, desarrollo económico.

Clasificación JEL: A10, D40, E24, 130, O10.

Abstract: As part of the great doctrinal event that Benedict XVI's encyclical letter Caritas in Veritate represents, bringing to the fore the central role that love and truth, gift and gratuitousness should play in sound and comprehensive reflections over human action, this article addresses the unpopular task of highlighting those technical solutions — as proposed in the Encyclical- that

* Doctor en Economía, Banco de España (www.bde.es). Anteriormente, Secretaría del Comité de Supervisores Bancarios de Basilea (Banco de Pagos Internacionales, www.bis.org), y Fondo Monetario Internacional (www.imf.org). El autor quiere expresar su agradecimiento a Jesús Huerta de Soto por sus comentarios y su apoyo, así como a los valiosos comentarios recibidos en sesiones de trabajo de la Asociación Española de Doctrina Social (www.aedos-dsi.com) y del Centro Diego de Covarrubias (www.centrocovarrubias.org). Cualquier error es atribuible exclusivamente al autor. Las opiniones que se expresan son exclusivamente las del autor (antonio.pancorbo@bde.es).

Procesos de Mercado: Revista Europea de Economía Política Vol. VIII, n.ำ 1, Primavera 2011, pp. 51 a 90 
might be questionable from the standpoint of economics. The article does not seek to correct these technical solutions. Rather, it intends only to elicit a fruitful discussion between economists and moralists on some specific points so that the two fields of knowledge may come together and offer guidelines for action that are not only morally sound, but also technically feasible.

Key words: Social Catholic thought, market structure, poverty, wellbeing, economic development.

JEL Classification: A10, B00, D40, E24, 130, 010.

\section{EL DIÁLOGO ENTRE LA CIENCIA ECONÓMICA} Y LA DOCTRINA SOCIAL DE LA IGLESIA

La Doctrina Social desarrollada por el Magisterio de la Iglesia ofrece unas reflexiones morales para iluminar la acción y el papel de los distintos agentes sociales: empresarios, trabajadores, gobernantes, asociaciones intermedias, familias, ancianos, minusválidos, niños, etc., ya que «toda acción social implica una doctrina» (cf PP 276-277). Fuera de este ámbito específico del desarrollo de principios y reflexiones morales, la última encíclica de Benedicto XVI, Caritas in Veritate, ${ }^{1}$ nos recuerda que «la Iglesia no tiene soluciones técnicas que ofrecer» $(C V 9){ }^{2}$ porque «al afrontar los fenómenos que tenemos delante, la caridad en la verdad exige ante todo conocer y entender, conscientes y respetuosos de la competencia específica de cada ámbito del saber» ( $C V$ 30). Sin embargo, ante la necesidad de hacer presentes sus reflexiones morales (por ejemplo, cómo hacer presente una sociedad solidaria, qué implica una actuación subsidiaria de los poderes públicos, en qué consiste un trabajo digno que dé espacio a lo trascendente, cómo luchar para la erradicación de la pobreza, etc.) algunos escritos del Magisterio proponen soluciones técnicas que entiende que son económicamente válidas. Es en el ámbito de la discusión de

\footnotetext{
1 En adelante, la Encíclica.

2 La delimitación de las enseñanzas de la Doctrina Social de la Iglesia al campo de la reflexión moral es doctrina común. Véase, por ejemplo: GS 36 y CA 43.
} 
estas soluciones técnicas donde se enmarca este artículo, y no en la discusión de los principios morales que ofrece el Magisterio.

La ciencia económica ofrece al pensamiento social cristiano el estudio de las «leyes» inscritas en la propia dinámica de la acción humana. ${ }^{3}$ Como meras observaciones de la realidad, expresivas de una concepción antropológica concreta, estas leyes son moralmente neutras. ${ }^{4}$ Que solo el interés lleva al hombre a actuar, que la abundancia de un bien económico tiende a bajar su precio, o que el establecimiento coactivo de precios máximos por debajo de lo que sería su nivel de equilibrio crea situaciones de escasez son fruto de la observación objetiva de la realidad, y como tales, no tienen calificación moral, simplemente están ahí (como el instinto maternal o el deseo sexual).

A diferencia de las leyes inscritas en la dinámica de la acción humana, no serán moralmente neutras las decisiones económicas que toman los individuos. La política económica, la gestión de negocios, o las decisiones individuales de comprar y vender son acciones morales, porque, como nos recuerda la Encíclica, «toda decisión económica tiene consecuencias de carácter moral» ( $\mathrm{CV}$ 37) Sin embargo, con independencia de su calificación moral, estas decisiones económicas han de respetar las leyes objetivas sobre las que razona la ciencia económica para que tengan los resultados pretendidos. Por lo tanto, el diálogo entre la economía y la Doctrina Social de la Iglesia es necesario.

En efecto, toda solución técnica derivada de las enseñanzas morales de la Iglesia debe cumplir con las leyes sobre las que razona una ciencia económica bien entendida. Cuando el Magisterio propone soluciones técnicas, sobre las que reiteradamente

3 Para una discusión sobre los contenidos de la ciencia económica puede consultarse: LUDWIG VON MisEs, La acción humana: tratado de economía, 10. edición, Unión Editorial, Madrid 2011. Véase también, RAFAEL RuBIO DE URQuía, «¿Qué es la Teoría Económica?», Revista Portuguesa de Filosofía, Monográfico sobre Filosofía y Economía, dirigido por J-J Vila-Chá, Tomo 65, Fasc. 1-4, 2009, pp. 519-548; y del mismo autor, "Claves de la actividad económica para un desarrollo sostenible en un mundo globalizado: una perspectiva cristiana», en: Eduardo Toraño y Javier Prades (Eds.), Dios es Amor, Facultad de Teología San Dámaso, Publicaciones San Dámaso, Madrid 2009, pp. 95-137.

4 Por «ley» se entiende aquellas relaciones de "causa y efecto», inscritas y observables en la misma naturaleza de la acción humana. 
reconoce no tener competencia, será responsabilidad de la ciencia económica discutirlas para asegurar que, además de ser moralmente correctas, sean también técnicamente posibles. Dada la autonomía de las ciencias en sus respectivos ámbitos del saber, la discusión sobre las soluciones técnicas que propone la Doctrina Social no entra en conflicto ni pretende cuestionar las enseñanzas morales de la Iglesia. Muy al contrario, este debate técnico sobre las recomendaciones para la acción colabora a perfeccionar lo que el Magisterio propone como moralmente deseable.

Sin embargo, la tarea no es tan simple. La economía no es una ciencia exacta, ni todas las escuelas de pensamiento económico son igualmente correctas a la hora de observar e interpretar la realidad social. Son numerosas las escuelas de pensamiento económico, y en ocasiones contrapuestas entre sí: keynesianismo, monetarismo, neoclasicismo, escuela austriaca, supply-siders, public choice, expectativas racionales, marxismo, etc. Ninguna escuela es aceptada universalmente como superior o incuestionable (aparte de por sus seguidores y por los grupos de influencia a los que da cobertura intelectual). Esta situación se ha hecho aún más evidente en la actual crisis económica mundial, al poner de manifiesto la incapacidad de la teoría económica dominante para entender y explicar los desequilibrios económicos, financieros y monetarios que se estaban produciendo y, que a la larga, provocaron la crisis. Esto puede significar que las soluciones técnicas que los economistas puedan haber ofrecido al Magisterio se deban replantear.

Entonces, ¿cuáles son las escuelas de pensamiento económico sobre las que se debería apoyar el Magisterio? Esto tampoco tiene una respuesta fácil. Ninguna escuela de pensamiento puede presentarse como la única compatible con el pensamiento social cristiano; si bien, algunas pueden ofrecer una explicación de las realidades económicas más cercanas a una concepción de la dignidad del hombre, creado con una voluntad libre y una inteligencia creadora a imagen y semejanza de Dios. Así, el Magisterio social debe permanecer muy abierto y escuchar a todas las escuelas de pensamiento económico, y comprobar si dicho pensamiento es compatible con la concepción cristiana del hombre.

El pasado nos ofrece buenos ejemplos de un pensamiento económico acertado basado en la comprensión católica del hombre. 
Sin quitarle ningún mérito al gran economista Adam Smith (1723-1790), quien por primera vez sistematizó la ciencia económica moderna, debería ser un motivo de orgullo para todos los católicos que cada vez sean más los estudios que identifican el origen de la economía moderna en el pensamiento de los escolásticos de la Escuela de Salamanca del siglo XVI. ${ }^{5}$ Estos dominicos y jesuitas no pretendieron escribir tratados de economía, sino dar instrucciones morales en una España que, de hecho, era unos de los principales centros financieros, económicos y culturales en esos momentos. Sin embargo, fruto de la observación de la realidad, y de acuerdo con su concepción de la persona y de la existencia humana, fueron los primeros en articular con éxito algunas de las principales leyes económicas, con capacidad explicativa de la coordinación social ya fuese el rey un santo o un tirano sin escrúpulos, ya estuviese la sociedad corrompida o llena de amor a Dios y al prójimo. Describieron, por ejemplo, el carácter individualista y subjetivo de los precios, costes y salarios, las bases que permitieron posteriormente entender la ley de la preferencia temporal, las leyes que subyacen en la teoría cuantitativa del dinero, los principios para una actividad bancaria sólida y estable, las leyes básicas del mercado, las consecuencias perturbadoras de la intervención del Estado. Retomaron y desarrollaron las ideas, ya presentes desde la Roma clásica, de que el desarrollo económico y la misma civilización son fruto de una acción descentralizada, que actúa en libertad, y nunca podrán ser el fruto del diseño de una mente centralizada, por brillante que ésta sea.

Por tanto, el debate sobre las soluciones técnicas que acompañan a los principios morales es necesario, y la crítica a estas

5 Véase, por ejemplo: AlejANDro CHAFUen, Raíces cristianas de la economía de libre mercado, El Buey Mudo, Madrid 2009; MArJorie Grice-Hutchinson, El pensamiento económico en España: 1170-1740, Crítica, Barcelona 1982; FRIEDRICK A. HAYEK, Law, legislation and liberty, Vol. II: «The mirage of social justice», The University of Chicago Press, Chicago 1976, pp. 178-179; RAYMOND DE ROOVER, «Economic thought, ancient and medieval thought», en: International encyclopedia of the social sciences, Press, Nueva York 1968; Murray N. Rothbard, "Capítulo 4. La escolástica hispana tardía», en: Historia del pensamiento económico. Vol. I: el pensamiento económico hasta Adam Smith, Unión Editorial, Madrid 1999; Jesús Huerta de Soto, La escuela austriaca: mercado y creatividad empresarial, cap. 3, Editorial Síntesis, Madrid 2000. 
soluciones técnicas que se encuentran en los documentos del Magisterio no se debe entender como un acto de rebeldía, sino parte del dialogo interdisciplinar que se busca desde la propia Iglesia. De hecho, soluciones técnicas equivocadas no son tanto errores del Magisterio como de los economistas que ofrecen su saber a quienes elaboran y redactan lo que se expresa en ese Magisterio. En este sentido, este artículo busca ser un elemento que estimule el debate y colabore con el deseo expreso de la Encíclica de que «la valoración moral y la investigación científica deben crecer juntas» (CV 31).

\section{II}

\section{EL ALCANCE DE LA INTERVENCIÓN DEL ESTADO EN LA ECONOMÍA}

Se puede argumentar que la actual Doctrina Social de la Iglesia tiene un sesgo a favor de la intervención del Estado en la economía que con frecuencia orienta las soluciones técnicas de los principios morales sobre los que reflexiona. "Ante el riesgo concreto de una idolatría del mercado» (CDSI 349), algunos de los enfoques seguidos en los textos de la Doctrina Social invitan a pensar que se trata de neutralizarlo proponiendo soluciones técnicas que buscan arrimarse a otro riesgo igual de nocivo: la idolatría del Estado.

La discusión de la intervención del Estado en la economía debe encontrar su punto de partida en el reconocimiento del principio de autoridad: "Toda sociedad humana tiene necesidad de una autoridad legítima, que asegure el orden y contribuya a la realización del bien común. Esta autoridad tiene su propio fundamento en la naturaleza humana, porque corresponde al orden establecido por Dios» (CCIC 405). En efecto, el principio de autoridad trasforma «un grupo de hombres» en comunidad propiamente dicha. Por otra parte, y en el orden económico, el Catecismo nos recuerda que «La actividad económica, en particular la economía de mercado, no puede desenvolverse en medio de un vacío institucional, jurídico y político. Por el contrario supone una seguridad que garantiza la libertad individual y la propiedad, además 
de un sistema monetario estable ${ }^{6}$ y servicios públicos eficientes.» ${ }^{7}$ (CIC 2.431, énfasis añadido).

Dicho lo cual, ni el principio de autoridad ni la necesidad de un marco institucional, jurídico y político para el desarrollo económico requieren la existencia del Estado moderno. El tiempo de los Jueces, antes de que el pueblo de Israel le pidiera al profeta y juez Samuel un rey como rechazo a que Yavé reinara sobre ellos (cf I Sam 8, 7), ${ }^{8}$ puede servir de ejemplo de sociedad articulada según el principio de autoridad en la figura de los jueces y una actividad económica fundada en la costumbre. Sin embargo, el economista y premio Nobel F.A. Hayek (1899-1992), constata el hecho de que en ningún proceso de evolución social hasta ahora ha surgido una sociedad sin Estado moderno, si bien, el proceso de evolución social continúa, por lo que hoy es imposible conocer si en el futuro el Estado, como lo conocemos hoy,

\footnotetext{
6 Un punto a considerar es si para garantizar un sistema monetario estable es necesaria la intervención del Estado. Las experiencias modernas de inflación e hiperinflación asociadas a la creación de dinero fiduciario para desempeñar la función social de «dinero», frente a la experiencia milenaria del oro y la plata como bienes económicos con la misma función social, han dado argumentos para discutir los beneficios de la exclusión del Estado a la hora de garantizar un sistema monetario estable. Ver, por ejemplo, Jörg GUIDO HüLSMANN, The ethics of money production, Ludwig von Mises Institute, Auburn AL 2008, http://mises.org/books/moneyproduction.pdf; GARY NorTH, Honest Money: The Biblical Blueprint for Money and Banking, 2005, solo disponible en Internet: http://www.garynorth.com/HonestMoney.pdf.

7 Servicios públicos que, no olvidemos, también se deben regir por el principio de subsidiariedad, donde el Estado debe ser el último recurso social a la hora de proveerlos.

8 Yavé accedió al reclamo del pueblo de Israel que pedía un rey, como el resto de naciones, pero le dijo a Samuel que les advirtiera con las siguientes palabras lo que realmente les traería ese rey: «Este será el derecho del rey que reinará sobre vosotros. Tomará a vuestros hijos, los destinará a sus carros de guerra y a su caballería, y ellos correrán delante de su carro. Los empleará como jefes de mil y de cincuenta hombres, y les hará cultivar sus campos, recoger sus cosechas, y fabricar sus armas de guerra y los arneses de sus carros. Tomará a vuestras hijas como perfumistas, cocineras y panaderas. Os quitará los mejores campos, viñedos y olivares, para dárselos a sus servidores. Exigirá el diezmo de los sembrados y las viñas, para entregarlo a sus eunucos y a sus servidores. Os quitará vuestros mejores esclavos, bueyes y asnos, para emplearlos en sus propios trabajos. Exigirá el diezmo de los rebaños, y vosotros mismos seréis sus esclavos. Entonces, clamaréis a causa del rey que os habéis elegido, pero aquel día Yavé no os responderá» (I Sam 8, 11-18).
} 
desaparecerá o quedará reducido a un Estado mínimo. ${ }^{9}$ En cualquier caso, «[1]a sabiduría y la prudencia aconsejan no proclamar apresuradamente la desaparición del Estado» (CV 41).

Aceptando, por tanto, la intervención del Estado en la economía, el Catecismo, nos recuerda que esta intervención ha de tener como función garantizar la libertad individual y la propiedad, «de manera que quien trabaja y produce pueda gozar de los frutos de su trabajo y, por tanto, se sienta estimulado a realizarlo eficiente y honestamente» (CIC 2.431). Este criterio dista mucho de justificar una intervención omnipresente del Estado en la economía. De hecho, el Catecismo también nos advierte que «una intervención demasiado fuerte del Estado puede amenazar la libertad y la iniciativa personales» (CIC 1.883). La acción coactiva del Estado esteriliza la creatividad de la sociedad y su capacidad para realizar actos libres y voluntarios. El absentismo y el desinterés por la vida social son situaciones que caracterizan a una sociedad fuertemente intervenida por el Estado, absorbiendo poco a poco «la nación, la sociedad, la familia, las comunidades religiosas y las mismas personas» (CA 45b). Así, la intervención del Estado no se debe prolongar en el tiempo, siendo éste un aspecto sistemáticamente incumplido por los gobiernos.

El Estado puede constituir una amenaza para la misma sociedad que lo crea, ya que entre los derechos cedidos por la sociedad se encuentra el «recurso a la violencia», lo que posibilita que el Estado pueda seguir absorbiendo más recursos y derechos de una sociedad que ha quedado indefensa. De ahí la importancia de mantener bien definidas las funciones del Estado, el modo de acceder al poder estatal, y de establecer estrictos controles democráticos en su funcionamiento. De otra forma, la coacción del Estado podría ser instrumentalizada por los partidos políticos y sus grupos de interés contra la sociedad y los miembros de otros grupos, al objeto de suprimir toda disidencia del pensamiento dominante y perpetuarse en el poder del Estado. Esta pugna real entre el Estado y la sociedad, de la que hoy somos testigos, debe

9 Friedrich A. HAYEK, La fatal arrogancia. Los errores del socialismo, Unión Editorial, Madrid 1990, pp. 10-20. 
ser motivo de profunda reflexión y denuncia profética por parte de la Doctrina Social de la Iglesia.

El referente moral que debe regir la intervención del Estado en la economía es el principio de subsidiariedad, «expresión de la inalienable libertad humana» (CV 57), mediante el cual «[u]na estructura social de orden superior no debe interferir en la vida interna de un grupo social de orden inferior, privándola de sus competencias, sino que más bien debe sostenerla en caso de necesidad y ayudarla a coordinar su acción con la de los demás componentes sociales, con miras al bien común» (CA 48). El Compendio de Doctrina Social indica que la acción del Estado «debe conformarse al principio de subsidiaridad y crear situaciones favorables al libre ejercicio de la actividad económica» (CDSI 351).

La necesidad de que el Estado tenga un carácter subsidiario está reafirmada en la propia Encíclica (CV 57 y 60). Sin embargo, a la hora de proponer orientaciones para la acción puede que la teoría económica dominante no haya sido de gran ayuda al Magisterio para proponer soluciones técnicas que promuevan un Estado de tipo subsidiario. La teoría económica dominante se encuentra fundada sobre postulados que justifican el intervencionismo estatal en la economía y desconfían de la capacidad de la sociedad para organizarse libremente a través de los procesos de mercado. Por otra parte, la realidad actual de gobiernos fuertemente burocratizados y con capacidad para manejar unos presupuestos elevadísimos, que frecuentemente superan la mitad del producto interior bruto, hacen que presentar «soluciones de mercado» a los principios morales que propone el Magisterio sea una posibilidad difícil, principalmente porque tales propuestas o están ausentes de los círculos de la ciencia económica actualmente dominante o no se comprenden.

Es decir, sobre una base doctrinal sólida del principio de subsidiariedad, las soluciones técnicas que plantea la Doctrina Social no son siempre respetuosas con este principio. A veces, se proponen orientaciones para la acción «impacientes», que ofrezcan soluciones inmediatas, casi mágicas, a través de una intervención demasiado fuerte del Estado en la economía (más allá de asegurar un marco jurídico que garantice la libertad individual y la propiedad) y, así, evitar el esfuerzo necesario de todos para solucionar 
los problemas económicos. Se le atribuyen al Estado una serie de deberes y competencias que deberían estar atribuidas, en primer lugar, al individuo, a la familia y a los diversos grupos y asociaciones en que se articula la sociedad, siendo el Estado el último recurso social.

El Compendio justifica la intervención del Estado «en los casos en que el mercado no alcanza a obtener los resultados de eficiencia deseados» (CDSI 353). ¿Resultados de eficiencia deseados por quién? Durante toda la historia, y en particular durante el siglo XX, se ha ganado experiencia de los peligros de permitir que los burócratas estatales monopolicen la responsabilidad de promover el bien común, que lo suelen identificar con sus intereses personales o de grupo. No es razonable poner una confianza excesiva e idealizada en la bondad de las administraciones públicas que ostentan poderes coactivos. Más cuando la propia Encíclica invita a no olvidar la realidad de que el hombre posee una naturaleza herida, centrada en sí mismo y en la idolatría del ego, lo que da lugar a graves errores en el dominio de la política y de la acción social (cf $C V 34$ ), y alerta contra una razón política que tiende a creerse omnipotente ( $c f C V 56$ ). La iniciativa privada comparte la misma naturaleza herida del hombre, pero con la diferencia de que, salvo que el Estado haya otorgado privilegios especiales o poderes coactivos a algún grupo, sus errores tendrán un impacto limitado y subsanable por la vía del derecho. Por otra parte, ¿cómo medir esos resultados de eficiencia? Ninguna situación económica llegará jamás a un punto donde no sea posible mejorar los niveles de eficiencia. En este sentido, toda situación económica es susceptible de entenderse por debajo de los resultados de eficiencia deseados, por lo que siempre habrá excusas para justificar la intervención del Estado.

El Compendio de Doctrina Social de la Iglesia entiende que «el Estado debe... dirigir con circunspección las políticas económicas y sociales» (CDSI 352). Sin ningún fundamento en la Escritura o de orden teórico (sin contar los fundamentos de los teóricos del intervencionismo), la Doctrina Social propone como deber la tutela del Estado para dirigir la actividad económica y social, anteponiéndola a la capacidad de la sociedad para desarrollar sus actividades económicas y sociales libremente, si bien con la 
cautela de no ocasionar «un menoscabo en las diversas actividades de mercado, cuyo desarrollo debe permanecer libre de superestructuras y constricciones autoritarias o, peor aún, totalitarias» (CDSI 352) . «El libre mercado puede proporcionar efectos benéficos a la colectividad solamente en presencia de una organización del Estado que defina y oriente la dirección del desarrollo económico» (CDSI 353, énfasis añadido). La supuesta función atribuida al Estado de «definir y orientar la dirección del desarrollo económico» no responde a una razón económica ni al principio de subsidiariedad. Está fundada en un pensamiento colectivista, rechazado explícitamente por la Iglesia (cf CIC 2.425), que entiende como bien superior la planificación centralizada de la economía.

Un pensamiento económico no intervencionista entenderá que el Estado no puede dirigir y orientar con éxito el desarrollo económico aunque quisiera. ${ }^{10}$ Los planificadores centrales no pueden sustituir la coordinación espontánea que surge de los procesos de mercado, donde los incentivos de productores y consumidores están alineados (producir lo mejor posible, lo más barato posible), ya que no dispone ni puede disponer de la información subjetiva sobre preferencias y objetivos de los millones de agentes que forman la sociedad, una información que, por otra parte, se está generando continuamente. Es decir, la dirección del desarrollo económico es algo que va definiendo la propia interacción social, siempre bajo el imperio de la ley y el principio de autoridad, y en un marco en que los incentivos de los agentes sociales tienden a estar en armonía más que en conflicto. Por otro lado, además de consideraciones morales y teóricas, la experiencia histórica de los regímenes colectivistas nos demuestra el fracaso de la planificación centralizada en la práctica.

En conclusión, es responsabilidad de la ciencia económica ofrecer al Magisterio alternativas a la intervención del Estado como orientaciones para la acción, de acuerdo con la advertencia de la

10 Véase: Ludwig von Mises, El Socialismo. Análisis económico y sociológico, 5. edición, Unión Editorial, Madrid 2007; FrIEDRICH A. HAYEK, Op. cit., pp. 10-20; Jesús Huerta De SOTO, Socialismo, cálculo económico y función empresarial, 4. a edición, Unión Editorial, Madrid 2010. 
Encíclica según la cual «[a] lo largo de la historia, se ha creído con frecuencia que la creación de instituciones bastaba para garantizar a la humanidad el ejercicio del derecho al desarrollo. Desafortunadamente, se ha depositado una confianza excesiva en dichas instituciones, casi como si ellas pudieran conseguir el objetivo deseado de manera automática» (CV 11).

\section{III \\ LA NECESIDAD DE UNA «AUTORIDAD POLÍTICA MUNDIAL»}

La Encíclica urge la creación de una Autoridad política mundial, «para gobernar la economía mundial, para sanear las economías afectadas por la crisis, para prevenir su empeoramiento y mayores desequilibrios consiguientes, para lograr un oportuno desarme integral, la seguridad alimenticia y la paz, para garantizar la salvaguardia del ambiente y regular los flujos migratorios» ( $\mathrm{CV}$ 67). La extensión de este artículo no permite ir punto por punto, pero desde la razón económica, estas necesidades (salvo los temas de desarme) no requieren la intervención de la autoridad política. Menos aún requieren que ésta sea mundial (que en temas de desarme su actuación podría ser dañina). Asimismo, la Encíclica defiende la necesidad de esta Autoridad política mundial para gestionar «una gran redistribución de la riqueza a escala planetaria como nunca se ha visto antes» ( $C V 42)$, punto que discutiremos más abajo, ya que la justicia distributiva tampoco es función de la autoridad política, sino una respuesta libre de la sociedad. La justicia distributiva es el resultado de «justicias distributivas» individuales.

Desconocemos las motivaciones profundas del Magisterio para incluir esta recomendación, pero desde una postura que rechace un relativismo moral que reivindique «presuntos derechos, de carácter arbitrario y voluptuoso, con la pretensión de que las estructuras públicas los reconozcan y promuevan» (CV 43), se entiende que la labor de la autoridad política no es tanto «inventar leyes», ni siquiera para un mundo globalizado, sino descubrir y legislar de acuerdo con aquellas leyes inscritas en el corazón del 
hombre y que la ciencia jurídica ha ido reflejando en los principios generales del derecho: «Oh Dios, da al rey tu juicio, al hijo de rey tu justicia: que con justicia gobierne a tu pueblo, con equidad a tus humildes» (Sal 72, 1).

Para esta labor de reconocimiento de la ley natural en el derecho positivo no es necesaria ninguna nueva autoridad política mundial. Cualquier grupo social puede y debe llevar a cabo esta labor de descubrimiento. Un cristiano debería reconocer que la única «autoridad mundial» es Dios que le ha dado al hombre la capacidad para discernir en su interior lo que es justo y bueno: «Conoceréis la verdad y la verdad os hará libres» $(J n$ 8, 32). En contraposición a una concepción de la sociedad por ideologías colectivistas y ateas, el Estado no es el árbitro entre el bien y el mal; la sociedad no lo crea para erigirlo como un nuevo dios, bien al contrario: «Decid entre las gentes: ¡Yahvé es rey! El orbe está seguro, no vacila; Él gobierna a los pueblos rectamente» (Sal 96, $10)$.

La Encíclica propone que esa Autoridad política mundial esté regulada por el derecho, se atenga a los principios de subsidiaridad y de solidaridad, y esté ordenada a la realización del bien común (CV 67), «organizada de modo subsidiario y con división de poderes» para «no abrir la puerta a un peligroso poder universal de tipo monocrático» (CV 57). Sin embargo, todo poder político ya debería ser «de tipo subsidiario, articulado en múltiples niveles y planos diversos, que colaboren recíprocamente» ( $\mathrm{CV}$ 57). La realidad, no obstante, demuestra que esto rara vez se cumple, y la tendencia con los continuos ataques a las libertades es a que cada vez se cumpla menos. Si es casi imposible encontrar en la práctica, de manera satisfactoria, autoridades políticas de tipo subsidiario y con una efectiva división de poderes, ¿cómo cabe entender que en el caso de una Autoridad política mundial, con la fortísima acumulación de poder que supone, vaya a producirse un poder político de tipo subsidiario, articulado en múltiples niveles? ¿No es excesivo el riesgo al que se expone el bien común con la implantación de una Autoridad política mundial que ni siquiera es necesaria? 
IV

UN PAPEL DEL ESTADO DESTINADO A CRECER

La Encíclica entiende que «Con relación a la solución de la crisis actual (2007), [el papel del Estado] parece destinado a crecer, recuperando muchas competencias» (CV 41). De la lectura completa del número 41, cabe suponer que el papel del Estado está destinado a crecer en aquello que implique «la consolidación de los sistemas constitucionales, jurídicos y administrativos en los países que todavía no gozan plenamente de estos bienes,... reforzar las garantías propias de un Estado de derecho,... y consolidar instituciones verdaderamente democráticas» ( $C V$ 41). Pero, fuera de esto y en relación con la solución de la crisis actual, no es doctrina pacífica que la solución pase por que el papel del Estado crezca y recupere muchas competencias, asumiendo que alguna vez haya perdido alguna. Recomendaciones que sean reflejo de ideologías intervencionistas, donde la solución de la crisis pasa por el crecimiento del Estado, no responderían a una necesidad moral.

Por otra parte, la idea de un papel del Estado destinado a «crecer y a recuperar muchas competencias», podría entrar en conflicto con el número 24 de la Encíclica donde, si bien reconoce que el Estado en estos momentos va a tener una intervención activa, indica que sería deseable que el peso de la sociedad civil creciese en la vida política:

Hoy, aprendiendo también la lección que proviene de la crisis económica actual, en la que los poderes públicos del Estado se ven llamados directamente a corregir errores y disfunciones, parece más realista una renovada valoración de su papel y de su poder,... Con un papel mejor ponderado de los poderes públicos, es previsible que se fortalezcan las nuevas formas de participación en la política nacional e internacional que tienen lugar a través de la actuación de las organizaciones de la sociedad civil; en este sentido, es de desear que haya mayor atención y participación en la res publica por parte de los ciudadanos (CV 24).

Existe un debate abierto sobre si la solución de la crisis actual puede venir del crecimiento del Estado, o si más bien el crecimiento 
del Estado es un impedimento para la solución de la crisis. Simplificando posiciones en contra del crecimiento del Estado como recomendación de política económica en momentos de crisis, el Estado debería abstenerse de cualquier tipo de intervención que retrase el proceso de ajuste necesario, que tiene que tener lugar para solucionar los excesos y permitir que la economía pueda recuperarse. Un uso discrecional de las políticas fiscales y monetarias como instrumentos contracíclicos en las etapas recesivas, puede que solo prolongue artificialmente la fase de «exuberancia irracional», pero no evita ni mitiga el proceso de ajuste en sí, lo agravaría haciendo más dolorosa la salida de la crisis. ${ }^{11} \mathrm{~A}$ esto, se pueden añadir las ocasiones en que los planes de estímulo de los gobiernos han respondido más a problemas políticos que económicos. Apoyar con recursos públicos a industrias o sectores sin viabilidad económica, intervenir en precios o salarios para salvar y prolongar situaciones económicamente insostenibles, o inflar de nuevo la moneda para tratar de salir de la crisis son actuaciones públicas muy discutibles.

Frente a soluciones técnicas que abogan por el crecimiento del papel del Estado, existen propuestas de reducir impuestos, poner más riqueza en manos privadas que impulsan los procesos de inversión productiva y recuperación económica; así como eliminar regulaciones que inhiben el desarrollo de la iniciativa privada. El Estado, entonces, no estaría llamado a crecer y recuperar competencias fuera de las que el Catecismo apunta como legítimas en el ámbito económico (garantizar la libertad individual y la propiedad), sino a menguar y a devolver el protagonismo económico, social y cultural a la sociedad. Por tanto, la orientación para la acción debe considerar fortalecer la salud moral de dicha sociedad que afronta situaciones de crisis, y no simplemente procurar cambios en enfoques de técnica política y económica.

${ }^{11}$ LUDWIG VON Mises, La acción humana: tratado de economía, 10. edición, Unión Editorial, Madrid 2011. 


\section{$\mathrm{V}$ \\ LA FUNCIÓN DEL ESTADO EN LA JUSTICIA DISTRIBUTIVA}

De acuerdo con el Catecismo de la Iglesia Católica (CIC 2.411), la justicia distributiva «regula lo que la comunidad debe a los ciudadanos en proporción a sus contribuciones y a sus necesidades». Es ante todo un síntoma de la salud moral de una sociedad, y un desafío a la lógica materialista por parte de Nuestro Señor Jesucristo que dijo: «mayor felicidad hay en dar que en recibir» (Hch $20,35)$. La lógica del don y de la gratuidad se presenta como una invitación de Cristo a todo hombre a encontrase con Él: «En verdad os digo que cuanto hicisteis a unos de estos hermanos míos más pequeños, a mí me lo hicisteis» $(M t 25,40)$.

La justicia distributiva apela a la conciencia libre del hombre: «El que tenga dos túnicas que las reparta con el que no tiene; el que tenga para comer que haga lo mismo» $(L c 3,11)$. Pero no se impone: «Cada cual dé según el dictamen de su corazón, no de mala gana ni forzado, pues Dios ama al que da con alegría» (2 Cor 9, 7). La justicia distributiva es un deber de caridad, que "pone al hombre ante la sorprendente experiencia del don» (CV 34), y surge una vez que el deber de justicia está satisfecho: «Cuando damos a los pobres las cosas indispensables no les hacemos liberalidades personales, sino que les devolvemos lo que es suyo. Más que realizar un acto de caridad, lo que hacemos es cumplir un deber de justicia» (San Gregorio Magno, Regula pastoralis, 3, 21, 45).

La Encíclica entiende que la actividad económica «debe estar ordenada a la consecución del bien común, que es responsabilidad sobre todo de la comunidad política. Por tanto,... la acción política ${ }^{12}$ tendría el papel de conseguir la justicia mediante la redistribución» (CV 36). En el número 37 se refuerza esta idea al indicar que la vida económica necesita «formas de redistribución guiadas por la política, además de obras caracterizadas por el espíritu

12 Comúnmente se entiende por «acción política» el conjunto de actos dotados de sentido y significación "política», es decir, relacionados con la conquista y el ejercicio del poder, para la construcción de un orden social según la ideología de quienes los realizan. 
del don». En la medida en que comúnmente se identifica la acción política con la acción coactiva del Estado, se debería eliminar de la justicia redistributiva la «acción política», casi siempre movida por intereses de grupo más que por un espíritu de servicio a la sociedad, para indicar que la vida económica necesita formas de redistribución guiadas y caracterizadas por el espiritu del don.

Anteponer la acción coactiva del Estado, el último recurso social, a la conciencia libre del hombre para alcanzar la justicia distributiva es optar por orientaciones para la acción influidas por ideologías políticas y económicas de tipo colectivista que dan prioridad a la acción del Estado sobre la sociedad civil. Estas orientaciones son, de hecho, las que con frecuencia se encuentran actualmente presentes en el Compendio de Doctrina Social de la Iglesia, según el cual es necesaria la intervención directa del Estado para poner por obra la justicia distributiva: «en algunos ámbitos, el mercado no es capaz, apoyándose en sus propios mecanismos, de garantizar una distribución equitativa de algunos bienes y servicios esenciales para el desarrollo humano de los ciudadanos: en este caso, la complementariedad entre Estado y mercado es más necesaria que nunca» (CDSI 353). Sin embargo, en aquellos ámbitos donde los mecanismos de mercado no sean suficientes para asegurar la justicia distributiva, antes que proponer la intervención del Estado habría que agotar todos los mecanismos de coordinación social que den primacía a la sociedad en lo que la Encíclica llama la «economía de la caridad» ( $C V$ 2), o la «economía de la gratuidad» (CV 38).

Puede que este deseo de la actual Doctrina Social de anteponer la acción del Estado a la acción de la sociedad para alcanzar la justicia distributiva se encuentre en una interpretación bienintencionada del deber del Estado de «inspirarse en el principio de solidaridad» (cf CDSI 351). Si la tarea del Estado en el ámbito económico se circunscribe a «definir un marco jurídico apto para regular las relaciones económicas» (cf CDSI 352), el deber del Estado inspirado en el principio de solidaridad se debe concretar y limitar a alcanzar la máxima eficacia posible en definir dicho marco jurídico que regule las relaciones económicas y que no obstaculice las iniciativas solidarias de la sociedad. La actuación solidaria, en su sentido amplio, es responsabilidad de los individuos 
que ejercen libremente su voluntad a través de sus propias actuaciones, y de los grupos y asociaciones en que se articulan, dentro de un marco jurídico definido por el Estado respetuoso con la ley natural.

Ninguna imposición coactiva del Estado puede considerarse una acción solidaria, porque la solidaridad, como hecho moral, nunca puede ser resultado de imposiciones legales, sino solo una respuesta de la conciencia libre del hombre. Indica el Compendio que «la subsidiaridad sin solidaridad corre el peligro de alimentar formas de localismo egoísta» (CDSI 352). Esto, en efecto, es así cuando una sociedad que dispone de un Estado de tipo subsidiario no dispone, asimismo, de una respuesta de apoyo solidario a aquellos segmentos más débiles de la población, considerándolos con indiferencia o como un peso, y no como un recurso que valorar. Situaciones de subsidiaridad sin solidaridad no son una llamada a los poderes públicos a imponer coactivamente actuaciones que tengan una apariencia externa de «actuaciones solidarias», sino a empeñarse en la formación de conciencias maduras, que superen la codicia y la idolatría de todo hombre a su ego, para poner en su lugar coherencia con los dictados de una conciencia madura que apela al hombre a la solidaridad.

El número 38 de la Encíclica rebaja la exigencia de la intervención del Estado, pero aún así con un sesgo que da a entender la primacía de su acción: «La solidaridad es en primer lugar que todos se sientan responsables de todos; por tanto no se la puede dejar solamente en manos del Estado.» Una presentación más consecuente con el principio de subsidiariedad rechazaría frontalmente la idea de que la solidaridad se pueda dejar en manos del Estado. No es su función promover la solidaridad, sino establecer un marco jurídico que regule las relaciones económicas y establezca los límites a la autonomía de las partes para defender a la más débil. La sociedad se articula libremente en grupos intermedios desde los que llevar a cabo la solidaridad.

El número 39 de la Encíclica, por su parte, reconoce la necesidad de dar mayor protagonismo a la sociedad civil: «El binomio exclusivo mercado-Estado corroe la sociabilidad, mientras que las formas de economía solidaria, que encuentran su mejor terreno en la sociedad civil aunque no se reducen a ella, crean 
sociabilidad. El mercado de la gratuidad no existe y las actitudes gratuitas no se pueden prescribir por ley. Sin embargo, tanto el mercado como la política tienen necesidad de personas abiertas al don recíproco.»

Es difícil desmontar uno de los mitos más arraigados en nuestra sociedad, incluso entre los fieles y personas de buena voluntad, que el Estado es el primer responsable de favorecer la redistribución de la riqueza en favor del bien común. A esto también se podrían añadir las teorías económicas distribucionistas, con fuerte raigambre entre ciertos pensadores católicos, ${ }^{13}$ que suelen ver con buenos ojos ideologías que abogan por economías planificadas y centralizadas.

Algo tan vulnerable a la corrupción y sustancial a toda sociedad como la justicia distributiva, se puede argumentar que no es prudente hacerlo depender de la acción política, lo que, por otra parte, reforzaría gobiernos ya de por sí excesivamente poderosos, estimulando mayores influencias políticas sobre ellos y mayor presión de los grupos de interés. Las obligaciones de la caridad son vinculantes a la conciencia de todo cristiano y persona de buena voluntad sin que dejen espacio para la acción coactiva del Estado. Así, los Padres de la Iglesia insisten «en la necesidad de la conversión y de la transformación de las conciencias de los creyentes, más que en la exigencia de cambiar las estructuras sociales y políticas de su tiempo, instando a quien desarrolla una actividad económica y posee bienes a considerarse administrador de cuanto Dios le ha confiado» (CDSI 328).

13 Por ejemplo, los británicos Gilbert Chesterton (1874-1936) y Hilaire Belloc (1870-1953). Análisis neo-distribucionistas, como JoHn MéDAILLE: Toward a Truly Free Market: A Distributist Perspective on the Role of Government, Taxes, Health Care, Deficits, and More, ISI Books 2010, plantean el distribucionismo en contraposición a un concepto erróneo de "capitalismo", que lo conciben como plutocracia amparada por los poderes coactivos del Estado, y no como sinónimo de economía de libre mercado basada en el derecho y la propiedad privada. 
VI

\section{EL «ESTADO DEL BIENESTAR»}

De acuerdo con la justicia distributiva y siguiendo los pasos de las obras de caridad fundadas por la Iglesia, hoy es comúnmente aceptado que la sociedad en su conjunto debe proveer ciertos servicios básicos y esenciales (alojamiento, vestido, comida, sanidad y educación) a aquellos individuos que por su incapacidad física o mental, o por una situación de desempleo tal no puedan proveerse por sí mismos.

De esta obligación moral de asistencia básica, que corresponde a la dignidad del hombre, se ha pasado en ocasiones a entender que la sociedad también está obligada en su conjunto a que los grupos más favorecidos ayuden a soportar el gasto en bienestar de los grupos menos favorecidos. A partir de ahí, ideologías de tipo socialdemócrata han creado y expandido el llamado «Estado del Bienestar». Bajo estos regímenes políticos, que se han ido implantando en la práctica totalidad de las economías avanzadas, es el Estado el responsable de organizar la redistribución de rentas de forma coactiva, proveyendo, además, servicios públicos que desplazan de forma intencionada cualquier tipo de iniciativa privada, de la cual se desconfía. Esta no es una opción política sin riesgo, «al intervenir directamente y quitar responsabilidad a la sociedad, el Estado asistencial provoca la pérdida de energías humanas y el aumento exagerado de los aparatos públicos, dominados por lógicas burocráticas más que por la preocupación de servir a los usuarios, con enorme crecimiento de los gastos» ( $C A 48)$.

En efecto, ¿cuál es el gasto en bienestar que debe proveer el Estado? En la lógica socialdemócrata, prácticamente cualquier necesidad que se pueda sentir, con una tendencia creciente a la mayor intervención posible del Estado en la economía y en la vida social. Cualquier necesidad que alguien pueda sentir se espera que la provea el Estado. Así, es posible ver conciertos de rock o lecciones de tai-chi como parte del llamado gasto social. La tendencia del Estado del Bienestar es a convertir cualquier necesidad en derecho, y a entender que por ser derecho debe estar financiado con los recursos de los contribuyentes, llegando a «la reivindicación del derecho a lo superfluo, e incluso a la transgresión y al vicio, 
en las sociedades opulentas» ( $C V$ 43). Mientras tanto se da «la carencia de comida, agua potable, instrucción básica o cuidados sanitarios elementales en ciertas regiones del mundo subdesarrollado y también en la periferia de las grandes ciudades» ( $C V$ 43).

La Encíclica, siguiendo el texto del Compendio de Doctrina Social de la Iglesia, defiende el «Estado del Bienestar» ${ }^{14}$ como un elemento del bien común. Así, el acertadísimo análisis de la Encíclica sobre la disminución de la natalidad como problema económico (cf $C V 44$ ), cita como la primera consecuencia adversa poner «en crisis incluso a los sistemas de asistencia social»; o el número 25 donde se denuncia que los procesos de competencia entre los estados con el fin de atraer centros productivos de empresas extranjeras «han llevado a la reducción de la red de seguridad social con grave peligro para los derechos de los trabajadores, para los derechos fundamentales del hombre y para la solidaridad en las tradicionales formas del Estado social».

En su número 57, sin embargo, la Encíclica cuestiona la posibilidad de una solidaridad que no sea respetuosa con la subsidiariedad y que «acabaría en el asistencialismo que humilla al necesitado»; y en el contexto de la discusión sobre un posible gobierno mundial, la Encíclica plantea el principio de subsidiariedad en tales términos que cuestionaría seriamente la primacía del asistencialismo público, destacando la finalidad emancipadora del principio de subsidiariedad, antes que cualquier modo de tutela permanente por parte del Estado.

Frente al Estado del Bienestar, que se ha erigido con el monopolio de la asistencia solidaria, conviene considerar alternativas orientadas al mercado del bienestar, donde no sería el Estado quien proveyera de servicios públicos para cubrir estas necesidades, sino que sería la iniciativa privada quien proveyera los servicios básicos, de sanidad y educación sobre todo, mediante, por ejemplo, la entrega de cheques asistenciales ${ }^{15}$ emitidos por asociaciones

\footnotetext{
14 La Encíclica se refiere al Estado del Bienestar al hablar de redes o sistemas de seguridad social, el Estado social o el gasto social.

15 Los subsidios de desempleo se pueden entender como «cheques asistenciales» para cubrir las necesidades de manutención y vivienda; ya que no es el Estado quien provee los economatos públicos o las viviendas públicas, sino que son los receptores
} 
mutuales voluntarias, fundaciones caritativas privadas o, como último recurso, apelando a la acción coactiva del Estado como sustituto de la asistencia solidaria.

El Estado del Bienestar es una solución técnica e ideológica de las ciencias políticas y económicas cuestionada seriamente tanto desde un punto de vista económico como moral. ${ }^{16}$ Tiende a eliminar enfoques más respetuosos con el principio de subsidiariedad, como las asociaciones fraternas o las asociaciones intermedias de ayuda mutua, promueve la "cultura de la dependencia del Estado", proponiendo el subsidio como modo de vida; ${ }^{17}$ trivializa el ahorro y se fomenta la irresponsabilidad individual; desconfía de la libertad, fundamento del cristianismo, y de la capacidad del hombre para prosperar por sus propias fuerzas; e infringe uno de los principios morales básicos: «el fin no justifica los medios», al emplear medios coactivos para sus fines, dando paso a la amoralidad. El Estado del Bienestar suele responde a intereses políticos antes que al bien común que dice promover, y económicamente es de naturaleza deficitaria y basado en un esquema de financiación de tipo «piramidal». Por último, el asistencialismo estatal que lo provee todo y cuida de todos contribuye a la descomposición de la familia al eliminar su función como primer recurso social de asistencia mutua. ${ }^{18}$

El «Estado del Bienestar», por tanto, no se puede entender como un bien moral que obligue a los católicos. Por el contrario,

de los subsidios quienes determinan dentro de la oferta de la iniciativa libre qué comida desean adquirir o qué tipo de vivienda desean ocupar.

${ }^{16}$ Véase:: THOMAs E. WoODS, La Iglesia y la economía: una defensa católica de la economía libre, Madrid, El Buey Mudo, 2010. ROBERT A. SIRICO, «Rethinking welfare, reviving charity: a Catholic alternative», en: Catholic social teaching and the market economy, (Philip Booth, ed.), Londres: Institute of Economic Affairs, 2007.

17 El asistencialismo estatal hace cierta la cita célebre del economista francés FREDERIC BASTIAT (1801-1850) donde el gobierno es «la gran ficción a través de la cual todo el mundo se esfuerza en vivir a expensas de todo el mundo» («El gobierno», en: Ensayos de economía política, 1848-1850)

18 En este sentido, la Encíclica pide que los Estados establezcan políticas que promuevan la centralidad y la integridad de la familia ( $C V$ 44). Sin embargo, no es el cometido de los gobiernos adoptar políticas ideológicas sobre la familia, sino simplemente reconocer en las leyes la centralidad e integridad de la familia, y no cuestionar o impedir con sus actuaciones dicha centralidad de la familia como célula de la sociedad, como ocurre en la actualidad. 
su bondad debe ser reconsiderada partiendo de la sugerencia de la propia Encíclica de revisar las políticas internas de asistencia y de «solidaridad social», aplicando a ellas el principio de subsidiaridad y «creando sistemas de seguridad social más integrados, con la participación activa de las personas y de la sociedad civil» $(C V$ 60).

\section{VII \\ LOS CONCEPTOS DE «DESIGUALDAD» $\mathrm{Y} «$ POBREZA RELATIVA»}

La pobreza es, sin duda, un mal social a combatir para liberar a los más débiles «de una condición de miseria y de esclavitud» (CDSI 325): «Dios bendice a los que ayudan a los pobres y reprueba a los que se niegan a hacerlo. ... Jesucristo reconocerá a sus elegidos en lo que hayan hecho por los pobres» (CIC 2.443).

Sin lugar a dudas, sufre pobreza material ${ }^{19}$ quien vive una situación de miseria deshumanizadora y quien no puede cubrir sus necesidades básicas de alimentación, vestido, alojamiento, sanidad y educación. Fuera de estas condiciones objetivas, definir la pobreza material no es sencillo, y menos en una cultura como la actual donde la tendencia es a admirar a los ricos y poderosos, hasta conseguir crear una visión corrompida de la pobreza que para el cristiano es «símbolo de la situación del hombre ante Dios» (CDSI 323): «A los ricos de este mundo recomiéndales que no sean altaneros ni pongan su esperanza en lo inseguro de las riquezas sino en Dios, que nos provee espléndidamente de todo para que lo disfrutemos» $(1 \operatorname{Tim} 6,17)$.

Frente a situaciones incuestionables de pobreza material, como las que viven buena parte de la población de los países subdesarrollados, con poderes públicos corrompidos que bloquean el ahorro y la producción como único modo de superar la pobreza, la pobreza material en los países desarrollados, donde la acumulación

19 El Catecismo de la Iglesia Católica, n. 2.444, indica que el amor de la Iglesia por los pobres abarca también formas de pobreza cultural y religiosa que no son el objeto de este artículo. 
de capital es posible y es un hecho, se ha convertido en un fenómeno marginal. Ante esta situación, los teóricos del Estado asistencialista de los países ricos y aquellos grupos de presión que viven de los presupuestos del Estado han formulado nuevas definiciones de pobreza que permitan seguir justificando cada vez mayores cuotas de gasto público «solidario». Equiparan «pobreza» con «desigualdad» para pasar a hablar de la «pobreza relativa». De este modo, países con rentas per cápita superiores a los 25.000 dólares anuales, llegan a presentar bolsas de «pobreza relativa» similares a situaciones objetivas de pobreza que existen en países subdesarrollados, con lo que se consigue justificar la expansión del llamado presupuesto social y la insensibilización en los países ricos de las situaciones objetivas de miseria.

La Encíclica también se refiere a la «desigualdad» como un mal social: «La riqueza mundial crece en términos absolutos, pero aumentan también las desigualdades» (CV 22). Cuando las desigualdades económicas han sido el resultado del engaño, la corrupción política, los abusos de poder, etc., la denuncia del Magisterio es inexcusable. Sin embargo, la desigualdad en sí no es un mal moral ni social, sino una característica de la creación, tanto en este mundo como en el venidero, donde en el cielo (cf $M t 5,19)$, en el infierno y en el purgatorio habrá diversos grados, así como hay desigualdades entre los mismos coros angélicos ( cf Col 1, 16). Las desigualdades tienen su explicación en el plan providente y misericordioso de Dios (cf CDSI 329) y permite honrar de manera especial cada una de las perfecciones divinas. ${ }^{20}$ Esto no es óbice para que la existencia en este mundo de desigualdades escandalosas que denuncia el Catecismo (cf CIC 1938) no sea una llamada a la reflexión y a la actuación moral del hombre.

Por tanto, denunciar «desigualdades» que no han sido el resultado de injusticias carecería de sentido ya que no todos somos ni seremos iguales, «a uno dio cinco talentos, a otro dos y a otro uno» $(M t 25,15)$. Más aún, denunciar desigualdades sería contraproducente al fomentar la envidia, una ofensa a Dios contraria a la caridad: «la caridad no es envidiosa» $(1$ Cor 13, 4). En los

20 Sta. Teresita del Niño Jesús, Historia del un alma, traducción de Manuel Ordóñez Villaroel, OCD, Monte Carmelo, Burgos 2003, p. 214. 
siguientes números, la Encíclica equipara de forma poco afortunada pobreza con desigualdad:

La dignidad de la persona y las exigencias de la justicia requieren, sobre todo hoy, que las opciones económicas no hagan aumentar de manera excesiva y moralmente inaceptable las desigualdades ...El aumento sistémico de las desigualdades entre grupos sociales dentro de un mismo país y entre las poblaciones de los diferentes países, es decir, el aumento masivo de la pobreza relativa, no sólo tiende a erosionar la cohesión social y, de este modo, poner en peligro la democracia, sino que tiene también un impacto negativo en el plano económico por el progresivo desgaste del «capital social» (CV 32).

El proceso de globalización, ... si se gestiona mal, puede incrementar la pobreza y la desigualdad (CV 42).

No tendría sentido como objetivo moral reducir las «desigualdades», menos aún reducir un concepto fuertemente ideológico como "pobreza relativa». El fin moral y económico que debe ser objeto de atención para todo cristiano y persona de buena voluntad es reducir la pobreza. Erradicarla de allí donde se dé en el mundo, siendo las situaciones de pobreza deshumanizadora que se ven hoy sobre todo en África y en otros lugares vergüenzas que claman al cielo.

Las orientaciones para la acción, pues, deberían considerar cómo establecer las condiciones necesarias que permitan la creación de riqueza, como modo más eficaz y duradero de erradicar la pobreza. Ante todo, crear un entorno de seguridad jurídica, libertad de iniciativa económica y respeto a los derechos de propiedad, en particular las propiedades de los más débiles frente a la codicia de los poderosos y la voracidad de las burocracias estatales. Un entorno que fomente el ahorro y la acumulación de capital bien invertido. ${ }^{21}$ Solo puede crearse riqueza si se produce

21 Frente a esta necesidad de la acumulación de capital para erradicar la pobreza, el número 40 de la Encíclica pone algunos frenos. Presenta una concepción «nacionalista» del capital que limitaría su capacidad para mejorar las condiciones de vida en las regiones donde se acumula y donde el marco institucional y social lo pueden 
la acumulación de capital físico (maquinaria, instalaciones, infraestructuras) y humano (formación), y se permite el crecimiento del llamado «capital social» (relaciones de confianza, fiabilidad y respeto mutuo) que permitan aumentar la productividad del trabajo, de modo que se pueda llevar a plenitud que «el amor a los pobres es también uno de los motivos del deber de trabajar, con el fin de hacer partícipe al que se halle en necesidad» ( $E f$ 4 , 28). ${ }^{22} \mathrm{El}$ antagonismo entre el capital y el trabajo del análisis marxista, que reclama la abolición de la propiedad privada, es puramente ideológico y contrario al pensamiento social católico (cf LE 11). Ambos, capital y trabajo, colaboran juntos para erradicar la pobreza como la teoría económica y la experiencia de las economías avanzadas nos enseña.

\section{VII \\ LA FUNCIÓN DEL ESTADO \\ EN LAS AYUDAS AL DESARROLLO}

El número 58 de la Encíclica ofrece unas reflexiones muy acertadas sobre la ayuda al desarrollo fundadas en el respeto al principio de subsidiariedad, y enfatizando que el recurso humano constituye el elemento más valioso de los países en vías de desarrollo, «es el auténtico capital que se ha de potenciar para asegurar a los países más pobres un futuro verdaderamente autónomo». También indica que «la ayuda principal que necesitan los países en vías de desarrollo es permitir y favorecer cada vez más el ingreso de sus productos en los mercados internacionales, posibilitando así su plena participación». Reconoce los peligros de dejar la ayuda al desarrollo en manos de los gobiernos, y denuncia que «algunos han temido con frecuencia la competencia

hacer más productivo; y ofrece un análisis parcial del fenómeno de la deslocalización que tiende a favorecer y a enriquecer las regiones donde el capital y el trabajo se localizan, normalmente las regiones hoy más desfavorecidas.

22 Será muy discutible cualquier solución técnica para crear riqueza que se fundamente en un mayor gasto público que, en sí, es estéril y esterilizante, ya que aunque cree una sensación momentánea de prosperidad, absorbe los recursos de la sociedad allí donde son necesarios para acumular capital y conseguir un desarrollo sostenible. 
de las importaciones de productos, normalmente agrícolas, provenientes de los países económicamente pobres. Sin embargo, se ha de recordar que la posibilidad de comercializar dichos productos significa a menudo garantizar su supervivencia».

Sin embargo, dentro de sus orientaciones para la acción, la Encíclica confía que «los estados económicamente más desarrollados harán lo posible por destinar mayores porcentajes de su producto interior bruto para ayudas al desarrollo, respetando los compromisos que se han tomado sobre este punto en el ámbito de la comunidad internacional» (CV 60). La ciencia económica viene siendo cada vez más crítica con este tipo de programas de fondos al desarrollo entre gobiernos, ${ }^{23}$ cuyos principales frutos han sido apoyar regímenes brutales y corruptos, desatar luchas políticas internas por hacerse con el control de esos «fondos de desarrollo», crear burocracias parasitarias a esos fondos de desarrollo, o destruir sectores productivos en los países receptores que pudieran ser competidores de los países donantes. Se podría concluir, pues, que las ayudas de tipo gobierno a gobierno han dado como frutos el aumento del estatismo, la anulación de la sociedad civil y, en general, el retraso del desarrollo, justo lo contrario de lo que la justicia reclama. Por otro lado, estos porcentajes del producto interior bruto como ayudas estatales al desarrollo buscan por parte de los países donantes distraer la atención del daño que se hace a los países más pobres con las políticas proteccionistas que la Encíclica también denuncia (cf $C V$ 22, 42)

Las reflexiones morales de la Doctrina Social de la Iglesia sobre el desarrollo son correctas, pero conviene revisar a la luz de la razón y la experiencia aquellas soluciones técnicas donde los gobiernos intervienen, bien sea como receptores o donantes de las ayudas al desarrollo. La experiencia ha demostrado su inefectividad y que solo han perjudicado a quienes pretendían ayudar. Recomendaciones del Magisterio como que las ayudas económicas al desarrollo «han de ser concedidas implicando no sólo a los gobiernos de los países interesados, sino también a los agentes económicos locales y a los agentes culturales de la sociedad civil,

23 Véanse, por ejemplo, la línea de investigación de economistas como PETER BAUER, Xavier Sala y Martín, y Hernando de Soto. 
incluidas las Iglesias locales» ( $C V$ 58), deberían ser reconsideradas para eliminar el papel de los gobiernos (bien directamente o a través de supuestas «ONGs» interpuestas) como receptores de los fondos, ya que ha sido precisamente la provisión masiva de estos fondos a gobiernos con debilidades institucionales lo que ha hecho tanto daño a tantos países subdesarrollados. ${ }^{24}$

Es labor de los economistas, pues, colaborar con la Doctrina Social a la hora de proponer orientaciones para la acción que sean moralmente aceptables, no ignoren las leyes de la economía y propongan soluciones que favorezcan y no perjudiquen a los países subdesarrollados. Un campo de investigación y desarrollo lo constituye la promoción en los países pobres de la seguridad jurídica, la libertad de iniciativa económica y el respeto de los derechos de propiedad, para posibilitar la implantación de una economía de mercado que fomente el ahorro, la inversión y cree riqueza.

IX

\section{EL «SALARIO JUSTO»Y EL «TRABAJO DECENTE»}

La Encíclica entiende que la dignidad de la persona y las exigencias de la justicia requieren que se siga buscando como prioridad el objetivo del acceso al trabajo por parte de todos (CV 32). Se resalta la relación entre pobreza y desocupación. Los pobres son en muchos casos el resultado de la violación de la dignidad del trabajo humano, bien porque se limitan sus posibilidades (desocupación, subocupación), bien porque se devalúan los derechos que fluyen del mismo, especialmente el derecho al «salario justo» y a un «trabajo decente» ( $C V$ 63). Lo que no dice la Encíclica, porque no es el área de competencia del Magisterio, es cómo se pueden alcanzar estos objetivos respetando las leyes de la economía. El tema es delicado, pues los temas laborales están exasperados a menudo artificialmente por una lucha de clases programada, lo que «debería llevar a liberarse de las ideologías, que con frecuencia

24 Véase, por ejemplo, Thomas E. Woods: Op. cit.; Philip Booth, «Aid, government and development», en: Catholic social teaching and the market economy, (Philip Booth, ed.), Institute of Economic Affairs, Londres 2007. 
simplifican de manera artificiosa la realidad, y a examinar con objetividad la dimensión humana de los problemas» (CV 22).

De acuerdo con la Encíclica, la palabra «decencia» aplicada al trabajo significa:

Un trabajo libremente elegido, que asocie efectivamente a los trabajadores, hombres y mujeres, al desarrollo de su comunidad; un trabajo que, de este modo, haga que los trabajadores sean respetados, evitando toda discriminación; un trabajo que permita satisfacer las necesidades de las familias y escolarizar a los hijos sin que se vean obligados a trabajar; un trabajo que consienta a los trabajadores organizarse libremente y hacer oír su voz; un trabajo que deje espacio para reencontrarse adecuadamente con las propias raíces en el ámbito personal, familiar y espiritual; un trabajo que asegure una condición digna a los trabajadores que llegan a la jubilación ( $C V$ 63).

Es decir, un trabajo decente es aquel cuyo salario es suficiente para: «que permita satisfacer las necesidades de las familias y escolarizar a los hijos sin que se vean obligados a trabajar; que deje espacio para reencontrarse adecuadamente con las propias raíces en el ámbito personal, familiar y espiritual; que asegure una condición digna a los trabajadores que llegan a la jubilación». Conseguir salarios suficientes para cubrir las necesidades personales y familiares es un logro social de primer orden. Algo que requiere el trabajo y el compromiso de todos y que solo se consigue con grandes dosis de sacrificio y honestidad. Conseguir salarios que sean suficientes no es algo que se pueda conseguir sin esfuerzo o simplemente mediante un decreto legislativo.

Una vez más, será muy útil aprender del esfuerzo realizado por las economías avanzadas donde se puede considerar que buena parte de su población goza de un salario suficiente, y no repetir los errores de aquellas sociedades que no gozan de dicha situación. Y una vez más, la lección es la misma: el esfuerzo necesario para conseguir salarios suficientes ha ido dirigido a incrementar la productividad de los trabajadores, principalmente mediante una acumulación de capital bien invertido gracias a la libertad de empresa y motivado por el ánimo de lucro. No hay atajos ni 
intervenciones mágicas de los estados decretando «salarios suficientes» sin que previamente se haya conseguido que la productividad del trabajo los justifique, de lo contrario tal imposición solo llevaría a deteriorar más la situación de los trabajadores.

La ventaja con la que cuentan las actuales economías subdesarrolladas es que no parten de cero; ya disponen de los recursos, la experiencia y la tecnología de las economías avanzadas. Además, cuentan con la flexibilidad que otorga la globalización y las posibilidades de deslocalización, y la mayor facilidad a los flujos migratorios. Esto puede hacer que el proceso de desarrollo en lugar de necesitar del esfuerzo y compromiso de cuatro o cinco generaciones solo requiera una. Pero en cualquier caso, 20, 30 ó 50 años de escasez, penalidad y trabajo decidido para la acumulación de capital serán necesarios en cualquier región que quiera salir del subdesarrollo. Solo hay que permitir que sea posible.

Un caso particularmente doloroso es el trabajo de los niños. Decretos legislativos que prohíban el trabajo de los niños cuando la productividad del trabajo de sus padres y hermanos mayores aún no es suficiente solo consiguen acrecentar el problema. Un gobierno de un país pobre que, ante presiones bienintencionadas de las sociedades opulentas, decrete la prohibición del trabajo infantil solo consigue crear situaciones de clandestinidad e indefensión en el trabajo de los niños, ya que sus ingresos, por ridículos que puedan parecer en una sociedad opulenta, son vitales para el sostenimiento familiar. Los tres niños de Fátima iban a trabajar de pastores a Cova de Iría, porque la productividad laboral de sus padres en Ajustrel en 1917 no les dejaba otra opción para el sostenimiento familiar. Ni la Virgen María ni el Ángel de Portugal les prohibieron trabajar. Todo lo contrario, se siguieron citando con ellos en su lugar de trabajo. Casi cien años después, tras el desarrollo económico de la comarca de Leiría, ya no se ven niños trabajando en Ajustrel. Ante una prohibición legal, los padres buscarán formas ilegales de trabajo para sus hijos, fomentando en los países pobres el problema de la venta de niños, la prostitución infantil o la contratación ilegal de niños sin ningún tipo de seguridad o protección en el trabajo.

La Encíclica entiende, asimismo, que será decente «un trabajo que consienta a los trabajadores organizarse libremente y hacer 
oír su voz» ( $C V$ 63). «La invitación de la doctrina social de la Iglesia, empezando por la Rerum Novarum, a dar vida a asociaciones de trabajadores para defender sus propios derechos ha de ser respetada» (CV 25). Sin embargo, la práctica de las asociaciones sindicales, «desde siempre alentadas y sostenidas por la Iglesia» ( $C V$ 64), en algunos casos ha pasado de las beneméritas asociaciones voluntarias de trabajadores para hacer oír su voz a auténticos grupos políticos de coacción. En este caso, nadie estaría obligado moralmente a apoyar asociaciones con tales tácticas de negociación que no ayudan a los trabajadores en su conjunto, sino solo al propio grupo que representan.

Los sindicatos, cuando exigen salarios por encima de los que se conseguirían sin una acción coactiva y apoyada por privilegios legales, son un freno a la creación de empleo, desatendiendo la invitación de la Encíclica a las organizaciones sindicales nacionales a que «vuelvan su mirada también hacia los no afiliados y, en particular, hacia los trabajadores de los países en vía de desarrollo» (CV 64). Por otra parte, ciertas regulaciones laborales impiden la creación de empleo o directamente lo destruyen cuando sobreprotegen al empleado activo en perjuicio del parado.

Practicas sindicales y legislaciones laborales que promuevan el desempleo deben ser calificadas como moralmente reprobables, ya que «El estar sin trabajo durante mucho tiempo, o la dependencia prolongada de la asistencia pública o privada, mina la libertad y la creatividad de la persona y sus relaciones familiares y sociales, con graves daños en el plano psicológico y espiritual» (CV 25). La profesión económica sensible con la condición de los trabajadores, de todos los trabajadores, parados y activos, debe colaborar con el Magisterio en una denuncia de las condiciones que impiden el empleo.

Por último, la Encíclica reclama el derecho de todo trabajador a un salario justo. Pocos temas son tan delicados y confusos como definir qué es un salario justo. Siendo el salario el «precio» de unos servicios productivos, y por similitud con el concepto de «precio justo» de la «teoría subjetiva del valor», introducida por santo Tomás de Aquino, posteriormente desarrollada por los escolásticos de la escuela de Salamanca, incorporada en el pensamiento económico moderno por el economista austriaco Carl Menger, 
y finalmente recogido en la carta encíclica Centesimus Annus, según la cual el precio justo es aquel «establecido de común acuerdo mediante una libre negociación» ( $C A 32$ ), el salario justo se puede definir también como aquel establecido de común acuerdo mediante una libre negociación: «[el amo de la viña] contestó a uno de ellos: "Amigo, no te hago ninguna injusticia. ¿No te ajustaste conmigo en un denario? Pues toma lo tuyo y vete"» $(M t 20,13)$.

Sin embargo, como indica el Catecismo: «El acuerdo de las partes no basta para justificar moralmente la cuantía del salario» (CIC 2434). Sin referencias al análisis marxista, el salario no es un precio más. Debe responder a la dignidad de quien trabaja. Es decir, el salario justo, además de ser un salario libremente pactado, debe reconocer la productividad del trabajador y, así, permitirle recoger los justos frutos de su trabajo, sin desposeerle mediante coacción o engaño de lo que es en justicia suyo. «No explotarás al jornalero» $(D t 24,14)$; «Mirad: el salario que no habéis pagado a los jornaleros que segaron vuestros campos está gritando; y los gritos de los segadores han llegado a los oídos del Señor de los ejércitos» (St 5, 4); «Pues yo, Yavé, amo el derecho y aborrezco la rapiña. Les daré el salario de su trabajo lealmente» (Is 61, 8).

Por el mismo motivo, salarios mínimos o salarios familiares decretados por ley, en la medida en que excedan la productividad del trabajo realizado, no se pueden considerar salarios justos, sino salarios propios de la lógica del don o de la economía de la gratuidad. Su retribución son actos de caridad del que hace con lo suyo lo que quiere y como tales no se pueden exigir coactivamente sin deteriorar las condiciones generales de empleo y perjudicar, por tanto, a los trabajadores que puedan estar buscando empleo.

\section{$X$}

\section{RELACIONES DE INTERCAMBIO ENTRE VALORES EQUIVALENTES}

El principal motor que hace que el mercado sea el proceso más eficaz para resolver el gran problema de la creatividad y la coordinación social es que "si un intercambio entre dos partes es voluntario, sólo se llevará a cabo cuando ambas partes crean que 
dicho intercambio las beneficia». ${ }^{25}$ No entender esto desvirtúa seriamente la misma naturaleza de los procesos de mercado. La Encíclica, sin embargo, continúa erróneamente con la concepción del intercambio de valores equivalentes que aparece en el Compendio de Doctrina Social de la Iglesia al indicar que el mercado se mueve, junto con la lógica del contrato, por la «regla del intercambio de equivalentes» (CDSI 349). ${ }^{26}$

Una cosa es que «el mercado está sujeto a los principios de la llamada justicia conmutativa, que regula la relación entre dar y recibir entre iguales» ( $C V$ 35), y otra muy distinta es que lo que se da y lo que se recibe sean valores equivalentes para quien da y para quien recibe. En los procesos de mercados no se producen relaciones de intercambio entre valores equivalentes. En un intercambio en condiciones de justicia y de libertad, ambas partes valoran más lo que reciben que lo que dan, ambas partes mejoran su situación tras un intercambio libre y justo, aunque no tienen por qué mejorarla en igual medida.

Por otra parte, el valor que tienen las cosas para un individuo no se puede medir y determinar su equivalencia con el valor que le da otra persona. Según la «teoría subjetiva del valor», a la que ya nos referimos antes, el valor de las cosas es algo subjetivo que depende exclusivamente de cada individuo. De acuerdo con Sto. Tomás y el pensamiento escolástico, las cosas no poseen un valor «objetivo» en sí mismas, ni por el trabajo empleado, como diría Karl Marx ${ }^{27}$ ni por su coste de producción, ni por el riesgo para obtenerlas, o por el ingenio para conseguirlas. ${ }^{28}$ Todo depende

25 Adam Smith: An Inquiry into the Nature and Causes of the Wealth of Nations (La riqueza de las naciones), Londres 1776. Idea que MiLton Friedman continua en Free to Choose, 1980.

26 «Si el mercado se rige únicamente por el principio de la equivalencia del valor de los bienes que se intercambian, ...» (CV 35); «la vida económica tiene necesidad del contrato para regular las relaciones de intercambio entre valores equivalentes» (CV 37); "caridad en la verdad significa la necesidad de dar forma y organización a las iniciativas económicas que, sin renunciar al beneficio, quieren ir más allá de la lógica del intercambio de cosas equivalentes...» (CV 38).

27 Karl Marx, Das Kapital, Kritk der politischen Oekonomie, Hamburgo 1867.

28 Una botella de Burdeos puede tener un valor inmenso para una persona y, a su vez, casi ninguno para otra, sin que haya nada objetivo en esa botella de vino que justifique su alto o nulo valor. 
del sujeto que valora según sus preferencias, objetivos, ideologías, creencias, posibilidades, necesidades, etc. En palabras del escolástico Diego de Covarrubias y Leyva: «el valor de una cosa no depende de su naturaleza objetiva sino de la común estimación subjetiva de los hombres, incluso aunque tal estimación sea alocada».

Esta percepción subjetiva del valor es un elemento que está prácticamente ausente en el pensamiento económico dominante, pues éste siempre tiende a tratar la información económica como si fuera de naturaleza objetiva y medible. El pensamiento económico dominante admite la posibilidad de «medir el valor» de las cosas por algún tipo de estándar objetivo, como el dinero, confundiendo valor y precio, y ser representado en una función matemática, no como metáforas de la realidad social, sino para agregar las distintas valoraciones de los diferentes individuos de una economía y planificar la economía. Si esto fuese posible, las ideas estatistas de planificación centralizada de la economía según ciertos modelos matemáticos serían posibles y, por tanto, sería razonable, entre otras cosas, volver a intentar los experimentos de los regímenes colectivistas. ${ }^{29}$

\section{XI \\ SOCIEDAD CIVIL, ESTADO Y MERCADO}

Una concepción correcta del mercado es esencial para poder interpretar con éxito los acontecimientos económicos. En este sentido, la Encíclica expone una buena caracterización del mercado: «Si hay confianza recíproca y generalizada, el mercado es la institución económica que permite el encuentro entre las personas, como agentes económicos que utilizan el contrato como norma de sus relaciones y que intercambian bienes y servicios de consu$\mathrm{mo}^{30}$ para satisfacer sus necesidades y deseos» ( $\left.C V 35\right)$.

29 Véase: Jesús Huerta de SOTO, Socialismo, cálculo económico y función empresarial,

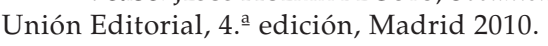

30 Habría que incluir igualmente «bienes y servicios de producción», o mejor dejarlo simplemente como bienes y servicios, ya que en el texto original en latín, tal limitación a bienes y servicios de consumo no está dicha: «Mercatus, si adsit mutua et pervulgata fiducia, est institutio oeconomica quae conventui favet hominum, quatenus 
El mercado es, por tanto, un proceso competitivo de descubrimiento y coordinación, ${ }^{31}$ respetuoso con la dignidad del hombre (cf CDSI 347), mediante el cual la sociedad se articula libremente para cubrir sus necesidades y prosperar. Desde esta caracterización es confusa la referencia que hace la Encíclica a «la necesidad de un sistema basado en tres instancias: el mercado, el Estado y la sociedad civil» (CV 38). Tanto el mercado, como el Estado como la sociedad civil son tres realidades de naturaleza muy distinta y no tres instancias a un mismo nivel. La doctrina católica da preeminencia a la dignidad del hombre que se desarrolla en la familia y decide voluntariamente asociarse en grupos intermedios, es decir, la sociedad civil se ha de situar en un plano superior tanto al mercado como al Estado, que quedan subordinados a ella y de los que se sirve para sus fines.

La Encíclica, haciendo referencia a la encíclica Centessimus Annus, continúa indicando que la sociedad civil es «el ámbito más apropiado para una economía de la gratuidad y de la fraternidad, sin negarla en los otros dos ámbitos [el mercado y el Estado]» (CV 38). Sin embargo, solo en la sociedad civil se puede dar una economía de la gratuidad y de la fraternidad, negándola en los otros dos ámbitos. El mercado y la economía de la gratuidad son dos procesos distintos de articulación voluntaria de la sociedad, que no están en contraposición ni son excluyentes, sino simplemente tratan de cubrir dos necesidades sociales distintas: la producción eficiente de bienes y servicios y la lógica del don. En el caso del Estado, su nulo papel en la economía de la gratuidad y la fraternidad es aún más claro. La economía de la gratuidad se fundamenta en la lógica del don, como un acto libre de la voluntad. Mientras que la lógica de la actuación del Estado se fundamenta

sunt operatores oeconomici qui utuntur contractu uti suarum necessitudinum norma et qui permutant bona et servitia inter se fungibilia ad proprias necessitates et desideria exsequenda».

31 Para una reflexión profunda sobre el mercado como proceso competitivo de descubrimiento y coordinación se pueden consultar las siguientes obras de IsRAEL KIRZNER, Competition and entreprenuership, 1973; Perception,opportunity and profit, 1979; y Discovery and the capitalist process, 1985. Todos ellos publicados por The University of Chicago Press, Chicago. E igualmente Jesús Huerta de Soto, The Theory of Dynamic Efficiency, Routledge, Londres y Nueva York, 2. a edición 2010. 
en la coacción, imponiendo acciones contrarias a la voluntad libre de los ciudadanos. Una economía de la gratuidad y de la fraternidad dirigida coactivamente desde el poder central del Estado es propia de ideologías de carácter colectivista.

Es importante, por tanto, distinguir la sociedad civil, «sujeto» del bien común, de los procesos e instituciones en que se articula para la promoción de dicho bien común: el mercado como proceso de descubrimiento y coordinación para la satisfacción eficiente de sus necesidades materiales, y el Estado como instrumento para garantizar el derecho.

\section{XII \\ LA ACEPTACIÓN DE LA LÓGICA DE LA EMPRESA PÚBLICA}

En cuanto al tema de la organización empresarial, la Encíclica aunque no defiende explícitamente la empresa pública, la sitúa en un plano de igualdad con la genuina iniciativa empresarial privada ( $C V$ 41). De acuerdo con el principio de subsidiariedad y la «reciente reafirmación del derecho natural a la iniciativa privada por parte de las más altas jerarquías católicas», 32 la empresa pública no tiene razón de ser en la medida en que una iniciativa empresarial pudiera estar cubierta por la iniciativa privada. Por empresa pública no solo entendemos la actividad empresarial de titularidad estatal, sino también empresas de titularidad privada que o bien reciben subvenciones significativas del Estado o gozan de privilegios legales que eliminan, restringen o desincentivan la competencia privada, originando monopolios, oligopolios o cárteles de naturaleza artificial y contrarios al bien común.

La empresa pública es un elemento antinatural en un mundo de iniciativa empresarial libre. La gestión de sus recursos no suele estar guiada por el autentico motor de progreso social que aporta la economía de mercado, es decir, satisfacer lo mejor posible las necesidades del mayor número de personas posible al mejor precio posible, sino por lógicas burocráticas e intereses políticos de partido.

32 Véase: Alejandro CHAFUen, Raíces cristianas de la economía de libre mercado, El Buey Mudo, Madrid 2009, p. 31. 
En ausencia de libre competencia, la empresa pública, tampoco cuenta con una información objetiva para saber si los recursos que utilizan están dirigidos correctamente a la producción de bienes y servicios más deseados por la población. Bajo la lógica política, los criterios sobre cuánto producir, dónde producirlo o usando qué materiales o métodos de producción serán políticos o ideológicos antes que económicos y de satisfacción de los verdaderos deseos y necesidades de la sociedad. El Estado, por otra parte, es un competidor privilegiado frente al resto de ciudadanos y grupos intermedios, que tiende a desalentar y esterilizar la iniciativa privada al hacerla inviable frente a los privilegios públicos, impidiendo que el protagonismo empresarial permanezca en la sociedad. En el caso de la empresa pública y las subvenciones estatales a la empresa privada, el Estado ya no es un árbitro imparcial que define «un marco jurídico apto para regular las relaciones económicas» (CDSI 352). Toma partido por un grupo concreto desincentivando la entrada de nuevos jugadores en esa competición.

La justificación técnica y moral de la empresa pública quedaría reservada para casos extraordinarios, y aún en estos casos su existencia debería ser transitoria, destinada desde su creación a devolver el protagonismo empresarial a la sociedad. Porque el principio de subsidiariedad «debe impulsar a las autoridades públicas a buscar las condiciones favorables al desarrollo de las capacidades de iniciativa individuales, de la autonomía y de la responsabilidad personales de los ciudadanos, absteniéndose de cualquier intervención que pueda constituir un condicionamiento indebido de las fuerzas empresariales» (CDSI 354). Es decir, la actuación del Estado debe estar orientada no hacia la tutela de la actividad económica, sino hacia su emancipación lo antes posible del Estado.

Desde esta perspectiva, no se comprende cómo el Compendio de Doctrina Social de la Iglesia atribuye al Estado «el deber de secundar la actividad de las empresas, creando condiciones que aseguren oportunidades de trabajo, estimulándola donde sea insuficiente o sosteniéndola en momentos de crisis» (CDSI 351). No es competencia del Estado el dirigismo de la actividad empresarial, ni mediante la titularidad de la actividad, ni mediante la concesión de subvenciones o de privilegios especiales. La Doctrina Social tiene un campo de denuncia en torno a la intervención 
estatal en la iniciativa empresarial, más si ésta surge o se mantiene con intención de permanencia. Estas intervenciones del Estado en favor de ciertas industrias y grupos de presión desvirtúan la libre competencia a favor de unos y en perjuicio de todos los demás creando situaciones de monopolio que son rémoras u obstáculos al desarrollo (cf CDSI 351).

\section{XIII \\ UNA VISIÓN NEGATIVA \\ DE LA ESPECULACIÓN FINANCIERA}

La Encíclica, al hablar de la empresa, indica que «Se ha de evitar que el empleo de recursos financieros esté motivado por la especulación y ceda a la tentación de buscar únicamente un beneficio inmediato, en vez de la sostenibilidad de la empresa a largo plazo» (CV 40). Ciertamente hay riesgos claros en seguir ciegamente una política miope en el empleo de los recursos financieros. Sin embargo, desde el punto de vista del correcto funcionamiento del mercado, tanto la especulación financiera como la sostenibilidad de la empresa a largo plazo son dos actividades necesarias para el desarrollo del tejido financiero y empresarial.

En principio, especular sobre los precios futuros según nuestra experiencia y conocimiento presente es parte de un proceso social y personal sano. Al posponer o adelantar la compra de un bien de consumo o de producción según nuestras expectativas de precios estamos especulando. De hecho, necesitamos especular sobre los precios para realizar cualquier actividad económica. Luego habrá habido o no un error, pero como seres humanos todos podemos y debemos especular sobre los precios y los cambios. Por otra parte, los especuladores financieros son piezas necesarias para el buen funcionamiento de los mercados. En su actividad de beneficiarse de posibles disfunciones en los precios, realizan dos funciones esenciales: eliminan impurezas en las formaciones de precios para que éstos puedan ser mejores transmisores de información sobre abundancia y escasez, y dan mayor liquidez.

Otra cosa distinta son las «escandalosas especulaciones» ( $\mathrm{CV}$ 65) que son moralmente reprobables. La Encíclica no especifica a 
qué se refiere, pero podemos entender como especulaciones escandalosas aquellas que (i) o bien se aprovechan de una manipulación artificial de los precios, (ii) o bien consiguen que los beneficios sean del especulador pero las pérdidas de toda la sociedad (generalmente gracias a algún tipo proteccionismo estatal). Por desgracia, estas formas inmorales de especular es lo que popularmente se asocia con la actividad de especulación y lo que ha provocado el juicio peyorativo que acompaña a esta actividad esencial dentro de toda economía de mercado.

En cuanto a la manipulación artificial de los precios como especulación escandalosa, el Catecismo de la Iglesia Católica indica que, «Toda forma de tomar... injustamente el bien ajeno, aunque no contradiga las disposiciones de la ley civil, es contraria al séptimo mandamiento», como, por ejemplo, «elevar los precios especulando con la ignorancia o la necesidad ajenas» (CIC 2.409). Y continúa diciendo: «Son también moralmente ilícitos, la especulación mediante la cual se pretende hacer variar artificialmente la valoración de los bienes con el fin de obtener un beneficio en detrimento ajeno... es contrario a la ley moral y exige reparación». Cabe incluir entre estas especulaciones escandalosas la fabricación de mentiras, normalmente tipificada como delito. También se podría considerar una forma de manipulación más sutil, a la que generalmente no se le da un juicio moral negativo, cuando ciertos grupos de intereses y de presión buscan la obtención de privilegios estatales que distorsionen o impidan la libre competencia con el fin de «elevar los precios especulando con la ignorancia o la necesidad ajenas».

La segunda forma inmoral de especulación financiera es aquella donde el especulador se apropia del beneficio y socializa las pérdidas. Una forma de actuar inmoral en los mercados que ha estado en el centro de la actual crisis económica mundial y que ha sido posible gracias a las garantías gubernamentales, explícitas e implícitas, directas o indirectas, a los especuladores, y por las políticas públicas de bajos tipos de interés y expansión artificial del crédito ${ }^{33} \sin$ respaldo de ahorro genuino que inducen malas

33 Véase: Jesús HuerTa de Soto, Dinero, crédito bancario y ciclos económicos, Unión Editorial, 5. - edición, Madrid 2011. 
inversiones que son insostenibles y que permitieron a los especuladores endeudarse hasta niveles que excedían su solvencia para aumentar sus apuestas. Esta forma inmoral de especulación financiera ha tomado especial auge por un mal uso en los últimos años de los llamados derivados financieros (futuros, opciones, CDS, etc.): apuestas apalancadas sobre la evolución de un activo subyacente. ${ }^{34}$

Las especulaciones escandalosas son reprobables, pero ir contra los especuladores de forma indiscriminada, sin atender a la moralidad y utilidad de sus actuaciones, es atacar superficialmente los síntomas y no las causas profundas.

\section{Acrónimos usados en este artículo}

CA, Juan Pablo II, Encíclica Centesimus annus, 1991.

CIC, Catecismo de la Iglesia Católica, 1997.

CCIC, Compendio del Catecismo de la Iglesia Católica, 2005.

CDSI, Compendio de Doctrina Social de la Iglesia, 2004.

$C V$, Benedicto XVI, Encíclica Caritas in veritate, 2009.

DCE, Benedicto XVI, Encíclica Deus caritas est, 2005.

GS, Concilio Vaticano Segundo, constitución pastoral, Gaudium et spes, 1965.

LE, Juan Pablo II, Encíclica Laborem exercens, 1981.

PP, Pablo VI, Encíclica Populorum progressio, 1967.

SRS, Juan Pablo II, Encíclica Sollicitudo rei socialis, 1987.

34 El Catecismo, en su número 2.413, nos recuerda que las apuestas no son en sí mismas contrarias a la justicia. La moralidad o inmoralidad de los juegos de azar dependerá del uso que se haga de ellos. 